\title{
Conferências EUCHEM
}

\section{ELECTRON MICROSCOPY IN SOLID STATE SCIENCE}

Lund, Sweden

20-24 May 1995

Organizer: Dr. J. O. Bovin

Inorganic Chemistry 2

Chemical Center, P.O. Box 124

21100 Lund, Sweden

Correspondence: Dr. A. Sjögren

The Swedish National Committee

for Chemistry

Wallingatan $243 \mathrm{tr}$

S 11124 Stockholm

tel. \# 4684115280

fax: \# 468106678

\section{SURFACE FORCES IN SCIENCE \\ AND TECHNOLOGY}

Stockholm, Sweden

15-17 June 1995

Organizer: J.C. Eriksson

Laboratory for Chemical Surface

Science Chemistry Departement

Royal Institute of Technology

S 10044 Stockholm, Sweden

Correspondence: Dr. A. Sjögren

see address above

CYCLOADDITIONS AND RELATED
REACTIONS: THEORY AND
PRACTICE
Isle of Vulcano, Sicily
21 -24 June 1995
Organizer: Professor Mario
Gattuso
Dipartimento di Chimica Organica
e Biologica
Università di Messina
Salita Sperone, 31
98166 S. Agata di Messina, Italy

MECHANISMS OF CHIRAL

RECOGNITION IN

CHROMATOGRAPHY AND

THE DESIGN OF CHIRAL PHASE

SYSTEMS

Göteborg. Sweden

14-18 August 1995

Organizer: Prof. S. Allenmark

Department of Organic Chemistry

University of Göteborg

S-412 96 Göteborg

Correspondence: Dr. A. Sjögren

see address above.

\section{$18^{a}$ Reunião Anual da Sociedade Brasileira de Química}

Subordinada ao tema “Melhor Qualidade através da Química", vai realizar-se de 30 de Maio a 2 de Junho, no Centro de Conferências do Hotel Glória em Caxambu, Estado de Minas Gerais, a $18^{a}$ reunião Anual da Sociedade Brasileira de Quimica
(SBQ), que engloba a realização, em paralelo, do $7^{\circ}$ Encontro Brasileiro de Fotoquímica.

Condicionada ao pagamento de uma taxa de incrição de US\$200, a participação nesta reunião permite a apresentação de duas comunicações científicas, sendo aceites resumos de comunicaçōes nas seguintes secçōes: Ensino da Química, Electroquímica e Electroanalitica; Estrutura Química e Actividade Biológica, Fisico-Quimica, Fotoquímica, História da Química, Produtos Naturais, Química Ambiental, Química Anali- tica, Química Biológica, Química de Materiais, Química de Superficies e Colóides, Química Inorgânica, Química Orgânica, Química Tecnológica e Quimica Teórica.

Para os interessados aqui fica o contacto da SBQ: Caixa Postal 20779, 01452 - São Paulo - SP.

\section{CHEMSPEC Europe 95}

A exposição CHEMSPEC EUROPE deste ano vai realizar-se na cidade alemã de Essen, de 21 a 22 de Junho. Organizada pela Paint and Chemical Division da FMJ International Publications
Ltd., contará com a presença de cerca de 240 empresas e comportara, em simultâneo, a realização de uma conferência técnica promovida pela British Association for Speciality Chemicals, subordi- nada ao tema "Chemical Aspects of drug Delivery Systems'"'.

Trata-se de um evento com particular interesse para químicos, farmacêuticos e industriais dos sectores agroquimico. cosméticos, limpeza, plásticos, borrachas, polimeros e tratamentos químicos. Mais esclarecimentos poderão ser obtidos pelo tel. 44. 0. 173776861 ou pelo fax 44. 0. 1737761685 .

\section{Comtox Symposium on Toxicology and Clinical of Metals}

Entre 10 e 13 de Julho, a Universidade da Columbia Britânica, em Vancouver, acolherá o simposio COMTOX, no qual se espera a presença de mais de quatrocentos cientistas com experiência em toxicologia, química clínica e analítica, patologia, distúrbios metabólicos, saúde ocupacional, ambiente e nutrição.

0 programa centraliza-se nas relações inter-disciplinares, incluindo, para além de uma vastíssima componente social, palestras, sessões de trabalho diversas e exposições alusivas aos temas em discussão, os quais, em relação ao programa cientifico, são: Biologia Molecular e Toxicologia de Metais, Análise de Metais nos Materiais Biológicos, Metais na Saúde e na Doença e Aplicações de Metais. Inscrições e esclarecimentos podem ser pedidos pelo tel. 203.679-2328 e pelo fax 203. 679-2154.

Por outro lado, e também na mesma Universidade, terá lugar de 18 a 23 de Agosto de 1996 a $31^{\text {a }}$ Conferência Internacional sobre Coordenação Química, que dedicará uma especial atenção aos sectores que, nesta área, assistem a um rápido desenvolvimento.
A data limite para inscrições e apresentação de resumos de participaçōes, que terão o inglês como língua oficial, é o dia 31 de Janeiro de 1996, sendo os contactos do secretariado da Conferência os seguintes: UBC Conference Center, 5961 Student Union Boulevard, Vancouver, BC, Canada V6T 2V9, tel: 604.8221050 , fax: 604. 8221069 . 


\section{Congresso}

\section{$3^{0}$ Encontro Nacional \\ de Didácticas/Metodologias da Educação}

\author{
END/ME \\ Instituto de Educação e Psicologia \\ Universidade do Minho \\ Campus de Gualtar
}

\section{Newsletter Scope}

0 Comité Científico para os Problemas do Ambiente do International Council for Scientific Unions vem publicando, já há alguns anos, a newsletter "Scope", particularmente vocacionada para dar a conhecer trabalhos e investigações cientificas acerca do ambiente. Os interessados em receber esta publicação deverão contactar o secretariado da SCOPE, 51, boulevard de Montmorency, 75016 Paris, França (tel: 33.1.45250498, fax: 33.1. 42881466).

\section{$15^{\circ}$ Congresso Internacional sobre Química Heterocíclica}

Vai realizar-se no Centro Internacional de Convenções de Taipé, entre 6 e 11 de Agosto, 0 $15^{\circ}$ Congresso Internacional sobre Química Heterocíclica, onde serão abordados os seguintes temas: Sintese Orgânica na Química Heterocíclica, assimetrias e heteroci- clos, fármacos e agro-químicos heterociclicos, reconhecimento molecular por heterociclos, química biorgânica dos heterociclos $e$ novos materiais.

0 inglês será a língua oficial desta conferência, que englobará ainda um riquíssimo progra- ma social e cultural.

0 prazo para inscrições está a decorrer, sendo a taxa de inscrição de 400 dólares e de 200 para estudantes.

Em complemento ao congresso, realizar-se-á na Universidade de Hong Kong, entre 13 e 16 de Agosto, um simpósio dedicado ao mesmo tema.

Os interessados em participar no Congresso deverão contactar o Prof. Chin-Kang Sha Department of Chemistry, National Tsing Hua University, Hsinchu 300, Taiwan, R.0.C.

\section{Euroanalysis IX}

Em Bolonha, entre 1 e 7 de Setembro de 1996, terá lugar a nona edição da Conferência Europeia sobre Química Analitica - EUROANALYSIS, que constitui, a exemplo de anteriores edições, um fórum altamente qualificado para a comunidade cientifica internacional, permitindo a troca de ideias e a apresentação e discussão dos mais recentes desenvolvimentos da Quimica Analítica.

Como principais tópicos das sessōes teremos: Educação, Validação na Química Analítica, Materiais de Referência, Calibração e Traçabilidade.

Os interessados em participar e em apresentar comunicações (a língua oficial de trabalho será 0 inglês, não estando prevista tradução simultânea) deverão contactar o mais cedo possivel a comissão organizadora através do Prof. Luigia Sabbatini, Dipartimento di Chimica, Campus Universitario, Via E Orabona, 4, 70126, Bari, Itália (tel: 39. 80. 242020/16/14, fax: 39. 80. 242026).

Aqui se deixa um particular apelo à participação dos quí- micos portugueseses nesta Conferência, que terá uma especia importância para Portugal na medida em que o nosso país através do Centro de Electroquímica e Cinética da Universidade de Lisboa, da Fundação da Faculdade de Ciências da Universidade de Lisboa, será responsáve pela organização da sua ediçāo do ano 2000.

\section{Euro Food Chem VIII}

As conferências bienais Euro Food Chem realizam-se desde 1981, primeiro em Viena depois em Roma, Antuérpia. Lovaina, Paris, Hamburgo e Valência. Este ano, de regresso à Áustria, a conferência terá lugar de 18 a 20 de Setembro, dedicando-se à análise da actual situação da Química alimentar e seus desenvolvimentos futuros, comportando igualmente uma exposição de equipamento científico $\mathrm{e}$ instrumentos analíticos, na qual podem participar empresas de todos os paises que se dediquem a esta área de produção, podendo para tal contactar a empresa Media Plan (Tel: 4315332199 , Fax: 4315356016 ).

\section{Fogos Industriais interessam Comissão Europeia}

No âmbito do programa europeu de pesquisa industrial, patrocinado pela DG XII, realizou-se em 11 e 12 de Março, na Holanda, o primeiro seminário europeu de pesquisa em fogos industriais. A crescente importância que 0 tema vem adquirindo em sede de trabalhos de investigação ditou que a DGXII publicasse agora as conclusões do seminário, nos campos da calorimetria, testes laboratoriais, fluidos computacionais, impacto de resultados e aplicações químicas ao tema. A publicação pode ser pedida ao Serviço de Publicações da CE, 2, rue Mercier, L - 2985 Luxemburgo. 


\section{Investigação financiada pela U.E.}

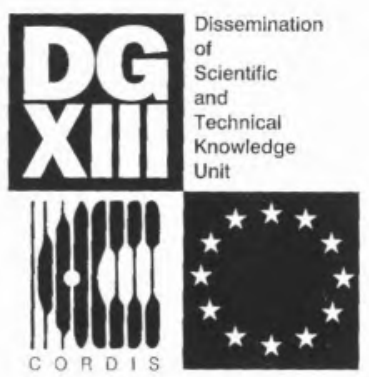

A investigação é, actualmente, um dos principais interesses $\mathrm{e}$ investimentos da União Europeia. Consciente das vantagens de um rápido acesso à informação existente sobre esta matéria, os serviços comunitários criaram e desenvolveram diversos sistemas de acesso a esta informação, nomeadamente, no que toca às áreas científicas, pela implementação do CORDIS - Community Research and Development Information Service - e pela difusão de informação técnica e científica na publicação "Euro Abstracts".

0 CORDIS, serviço prestado pela DG XIII da Comissão Europeia, faz parte do programa VALUE (Valorisation \& Utilisation), criado para estimular a exploração e a promoção dos resultados da investigação tecnológica dentro da Comunidade.

A informação está disponivel através de 9 bases de dados "on line" (gratuito, excluindo 0 preço de uma chamada telefónica local), CD Rom e documentação em suporte papel. Mais informações acerca deste serviço podem ser obtidas junto do European Commission Host Organisation, CORDIS Costumer Service, BP 2373, L 1023 Luxembourg, ou ainda ligando o telefone 0505 52002 (grátis); ou contactando a JNICT, Centro Value Portugal (tel: 7271365/81).

Quanto à publicação "Euro Abstracts", trata-se de um guia geral das publicações da U. E. , no qual a investigação está organizada a partir de tópicos como
Química, Ciências da Terra, Engenharia e Tecnologia, Energia, Ciências da Vida, Ciência e Engenharia Nucleares e Tecnologias da Informação e Comunicaçăo. Considerado o tópico pretendido. é fornecido um breve resumo da publicação e detalhes sobre onde e como a obter. Mensalmente, a "Euro Abstracts" inclui artigos mais detalhados acerca de I \& D, podendo ser recebida pelos interessados mediante contacto para - Departamento das Publicações Oficiais das Comunidades Europeias, 2 rue Mercier, L 2985 Luxembourg (tel: 352499281 , fax: 352 488573)

\section{"Às voltas" com a Origem da Vida}

Na Science 267 de Março de 1995 apareceu um artigo bastante interessante sobre "The Origin of Homochirality in Life", um Congresso que se realizou em Sta. Mónica (Califórnia) em Fevereiro deste ano.

0 debate tipo "o ovo e a galinha" aplicado à homoquiralidade e à Vida já vem de há algum tempo. Porque é que as moléculas de açúcares do ADN

\section{0 portunidades}

\section{de carreira na Europa}

Segundo um artigo publicado recentemente na revista Science (267 (1995) 1205) a biotecnologia é apontada como uma área promissora para os próximos tempos, sobretudo no tocante ao número de oportunidades de emprego oferecido a cientistas. A descoberta de novas drogas, a utilização de métodos inovadores de controlo de doenças e a importância cada vez maior do computador como ferramenta de trabalho do investigador na identificação de novos centros activos através de "libraries" de moléculas, têm revitalizado esta área e aumentado 0 interesse de empresas multinacionais farmacêuticas. Cientistas e gestores de sete empresas euro- se "viram" para a direita e os amino-ácidos para a esquerda, em todos os organismos vivos ninguém sabe. Seria assim antes de haver Vida ou terá sido a Vida que determinou esta homoquiralidade? Associada a esta questão aparece uma outra que parece fantasiosa: terá a Vida começado na Terra ou algures no Espaço? Por isso está a ser preparada uma experiência, para 0 ano
2003, que tentará determinar a existência de homoquiralidade no cometa Wirtanen.

Estas questões e hipóteses são debatidas à luz de que quer os açúcares quer os amino-ácidos existem na Natureza em misturas racémicas mas, no entanto. só um dos enantiómeros de cada um deles ser utilizado pelos seres vivos.

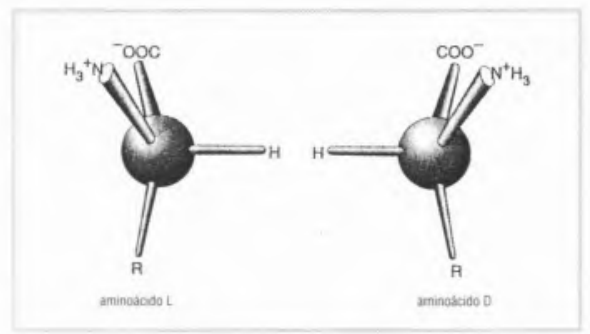

peias (Hoechst, Novo Nordisk. Unilever, Transgène, Wellcome, Introgene e Cambridge Antibody Technology) são entrevistados no artigo citado sendo a concordância geral: impõem-se cada vez mais o conceito de uma Europa cientifica sem barreiras físicas que ponham entraves à livre circulaçẫo de "massa cinzenta". Existe uma procura acentuada de cientistas de qualidade por toda a Europa, sendo identificados quatro elementos que podem fazer a diferença num concurso: excelência numa área pertinente; bom conhecimento em áreas relacionadas; experiência na indústria; e suficiente flexibilidade para mudar de área ou tema de investigação.

\section{$2^{\circ}$ Encontro de Química Física}

A Divisão de Química-Física da Sociedade Portuguesa de Quimica vai levar a efeito na Casa do Vilar (Porto), de 21 a 23 de Junho próximo, o $2^{\circ}$ Encontro Nacional da Química-Fisica. 0 programa científico é constituido por cinco lições plenárias, dezoito convidadas e ainda por comunicações em painel submetidas pelos participantes.

0 custo da inscrição, incluindo 2 almoços e 4 cafés é de $10000 \$ 00$ para sócios da SPQ, $5000 \$ 00$ para não licenciados e $15000 \$ 00$ para os restantes participantes.

Para mais informações

e correspondência contactar:

Prot. J.A.N. Ferreira Gomes

Faculdade de Ciências

4050 Porto

Tel. (02) 2082135

Fax (02) 2008628

e-mail quimfis@fc.up.pt 


\section{Uma bola de ténis \\ molecular}

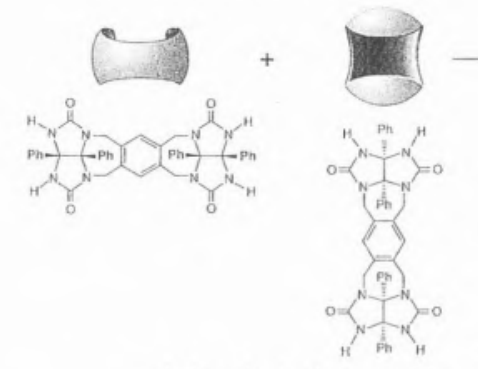

A descoberta da geometria dos fullerenos originou muito provavelmente uma ligação inquebrantável entre a química e o futebol. 0 mais falado, $0 \mathrm{C}_{60}$ (futeboleno na gíria), tem a estrutura de uma bola de futebol, formado portanto pela alternância entre hexágonos e pentágonos adjacentes.

Um grupo de químicos surgiu agora com uma nova analogia químico-desportiva: a bola de ténis molecular (Science, 263. (1994), 1222 e 1267.).

Enquanto os fullerenos se formam quando muitas unidades individuais de carbono se encontram na chama de um arco eléctri- co, as "bolas de ténis" tomam a sua forma em solução, à temperatura ambiente, quando dois componentes moleculares relativamente complexos (ver figura) se encontram.

Uma das prováveis aplicações futuras destes agregados moleculares, é a sua capacidade de enclausurar no seu interior outras moléculas - tipicamente derivados químicos agindo como drogas medicinais - transportando-as para 0 interior de células. $\mathrm{Na}$ fase presente destas investigações ainda se está longe de atingir este objectivo, mas o trabalho iniciado tem pelo menos o mérito de transpor conceitos biológicos, como sejam a auto-construção e auto-replicação molecular para a área da síntese química.

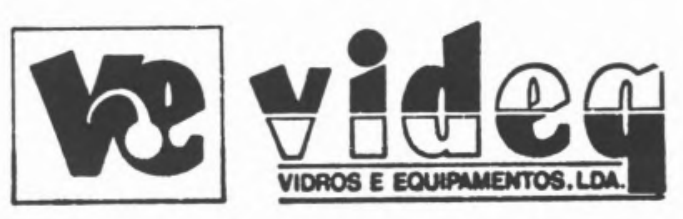

\section{Equipamento de Laboratório}

Balanças - Centrífugas - Aparelhos de $\mathrm{pH}$

Tituladores - Condutimetros - Agitadores

Espectrofotómetros - Microscópios - etc.

\section{Vidros e Plásticos de Laboratório}

Distribuidores NORMAX

\section{Material Didáctico}

Ensino Secundário e Superior

Representantes exclusivos

SISTEDUC - Sistemas Educativos S.A.

Rua Soeiro Pereira Gomes, 15 r/c Frente

Bom Sucesso - 2615 Alverca

Telefs. (01) 95704 20/1/2 - Fax (351-1-957 04 23) - Portugal 8th INTERNATIONAL WORKSHOP ON GLASSES AND CERAMICS FROM GELS

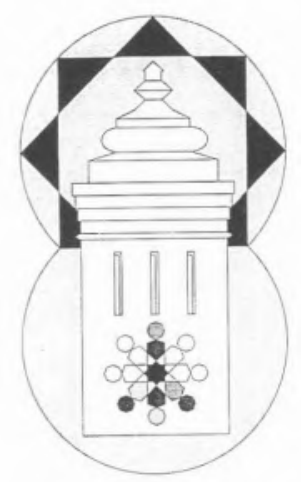

Faro, PORTUGAL 18-22 SETEMBRO, 1995

\section{COMISSÃO ORGANIZADORA:}

Chairman Rui M Almeida (I.S.T., Lisboa)

Vice-chair: Laura M. Ilharco (I.S.T., Lisboa)

Secretariado: M. Clara Gonçalves (I.S. T., Lisboa) M. Isabel Barros Marques (I. S. T., Lisboa)

M. Gracinda Ferreira da Silva (Univ. Aveiro) Isabel M. Salvado (Univ. Aveiro)
Trata-se da oitava Conferência Internacional duma série que foca os últimos avanços na Ciência e Tecnologia Sol-Gel, um campo multidisciplinar em rápido crescimento. O objectivo da $8^{\text {th }}$ Workshop é aproximar experimentalistas e teóricos de campos como Ciência de Materiais, Física, Quimica e Electrónica, que trabalham na fabricação, caracterização e modelização de vidros e cerâmicos preparados pelo processo sol-gel

Tópicos principais:

- Cinética e mecanismos do processo sol-gel

- Estrutura e propriedades do xerogel e do aerogel

- Envelhecimento, secagem e sinterização de geles em

volume e em filmes finos

- Vidros, cerâmicos, fibras, revestimentos e filmes derivados de sol-gel

- Vidros e cerâmicos modificados orgânicamente

- Catalisadores, membranas, ferroeléctricos

- Compósitos e nanocompósitos; nanoestruturas

- Óptica sol-gel, óptica integrada e não linear

- Materiais sol-gel dopados e dispositivos para lasers e amplificadores.

\section{Para mais informações, contactar:}

Rui M. Almeida

Departamento de Engenharia de Materiais

Instituto Superior Técnico

Av. Rovisco Pais, 1000 Lisboa

Tel: $01-3100371 / 8418135$

Fax: 01- 8499242 / 3524372

E-mail: MX\%"D1323@ß.IST.UTL.PT" 